\title{
SOCIEDADE DA INFORMAÇÃO, CRIMES E DIREITOS HUMANOS SOB O VIÉS DOS PAÍSES CENTRAIS E PERIFÉRICOS
}

\author{
${ }^{1}$ Celso Antonio Pacheco Fiorillo \\ ${ }^{2}$ Greice Patricia Fuller
}

\section{RESUMO}

O trabalho analisa a questão inerente à sociedade da informação e aos crimes digitais em face dos direitos humanos frente aos países centrais e periféricos. Os questionamentos partem da conceituação dos cibercrimes, considerando-se criticamente os direitos por eles violados e o direito de acesso ao uso da internet como sendo ambos direitos humanos. Ao final, discute-se criticamente - através de análise pautada no tríduo conceitual: sociedade da informação, realidade fenomênica e países centrais e periféricos - a segregação cibernética construída em face da realidade ditada pelo genocídio da dignidade da pessoa humana.

Palavras-chave: Sociedade da Informação, Crimes, Direitos Humanos, Países Centrais e Periféricos

\section{SOCIEDAD DE LA INFORMACIÓN, CRÍMENES Y DERECHOS HUMANOS FRENTE A LOS PAÍSES CENTRALES Y PERIFÉRICOS}

\section{RESUMEN}

El trabajo analiza la sociedade de información y los delitos digitales frente a los derechos humanos en los países centrales y periféricos. Las preguntas parten de la definición de cibercrímenes, considerándose los derechos que son violados y el derecho de acceso al uso de internet como derechos humanos. Más adelante, se considera de manera crítica - a través de un análisis basado en trinidad conceptual: sociedad de la información, realidad fenoménica y países centrales y periféricos la segregación cibernética como realidad dictada por el genocidio de la dignidad de la persona humana.

Palabras-claves: Sociedad de la Información, Crímenes, Derechos Humanos, Países Centrales y Periféricos

\footnotetext{
1 Doutor pela Pontifícia Universidade Católica de São Paulo - PUC, São Paulo (Brasil). Professor das Escolas Superiores da Magistratura Federal no Rio Grande do Sul - ESMAFE, Rio Grande do Sul (Brasil). E-mail: celsofiorillo@uol.com.br

2 Doutora pela Pontifícia Universidade Católica de São Paulo - PUC, São Paulo (Brasil). Professora pela Centro Universitário das Faculdades Metropolitanas Unidas - FMU, São Paulo (Brasil). E-mail: greicepf@uol.com.br
} 


\section{INTRODUÇÃO}

O presente estudo visa analisar as questões inerentes à sociedade da informação e aos crimes praticados no meio ambiente digital (também denominados cibercrimes ou crimes informáticos), sob o viés dos direitos humanos em face dos países denominados periféricos e centrais, impondo-se, inicialmente, o levantamento da problemática inerente à conceituação deste gênero delitivo. Posteriormente, observa-se que para além da problemática acima traduzida, o tema requer cuidado profundo no que pertine à questão referente à natureza dos direitos violados nas condutas praticadas no seio das novas tecnologias de informação e comunicação e razão justificante para sua tutela jurídico-penal.

Para além disso, verifica-se a problemática discutida em relação à natureza do direito de acesso ao uso da internet como direito erigido à categoria de direito humano, segundo relatório estabelecido pela Organização Nações Unidas (ONU) e argumenta-se teleologicamente sobre suas bases fático-teóricas.

Por fim, estabelecendo-se um corte epistemológico sobre o tema, analisa-se o quadro atinente à sociedade da informação subsumida na realidade dos países ditos centrais e periféricos, sob a ótica crítico-argumentativa.

Justifica-se a escolha temática por seu posicionamento vanguardista junto à realidade fenomênica do século XXI, instigando a razão e a alma na busca de levantamento das raízes de problemas caracterizadores de violações constantes aos chamados direitos humanos. A segregação - econômica, social e, cibernética - é uma realidade ditada não apenas por um mero formalismo conceitual entre países centrais e periféricos, senão e sobretudo, por uma marcha histórica e real de um genocídio cultural e da dignidade da pessoa humana que sangra nas veias daqueles que respiram, vivem e morrem em razão dela.

Desenvolveu-se o método indutivo para a análise sistemática do tema, partindo-se da observação fática, normativa e doutrinária para o reconhecimento da conclusão final sobre o quadro referente à sociedade da informação e seu aporte tipológico criminal em face dos direitos humanos e da relação dialógica entre os países centrais e periféricos.

\section{CRIMES NA SOCIEDADE DA INFORMAÇÃO}

\subsection{BREVES COMENTÁRIOS SOBRE SOCIEDADE DA INFORMAÇÃO}

Observa-se que os instrumentos de comunicação traduzidos pela informática e pelas telecomunicações vem gerando uma mudança na organização social, no que tange ao trabalho, administração, lazer, economia e relações interpessoais, contemplando-se cada vez 
mais a sociedade dita global, ou seja, uma sociedade que transcende nosso "entorno social mediato"1 para deitar suas raízes em todo o planeta. Falamos assim da sociedade da informação.

A revolução tecnológica ${ }^{2}$ que teve seu início com o fim da Segunda Guerra Mundial e início do período denominada Guerra Fria, alterou as estruturas existentes na sociedade, notadamente na área de comunicação, apresentando como principal característica o amplo acesso à informação, razão essa da expressão sociedade da informação.

Importante apenas esclarecer que a Sociedade da informação não apresenta seu âmbito de abrangência apenas ao uso da internet, mas também a qualquer outro meio de comunicação, a saber: televisão, rádio e telefone. Portanto, para além dos inegáveis efeitos positivos trazidos às sociedades, o advento dos novos meios de comunicação, em especial da Internet, dada a vulnerabilidade dos limites de seu uso, traz riscos ao bem estar comum e a valores constitucionais, visto que se está diante de um mundo virtual, no qual cada indivíduo é capaz de liberar suas inquietudes e anseios de uma forma anônima ${ }^{3}$.

\subsection{TIPIFICAÇÃO DE CONDUTAS E MEIO AMBIENTE DIGITAL: "ADMIRÁVEL REALIDADE DE UM MUNDO NOVO”?}

\subsubsection{MEIO AMBIENTE DIGITAL E CRIME}

\footnotetext{
${ }^{1}$ CLOTET, Juan Salom. Delito informático y su investigación, p.93. In: Vazques Nuñez, Eloy. Delitos contra y através de las nuevas tecnologías. ¿Cómo reducir su impunidad? Cuadernos de Derecho Judicial, III. Madrid: Consejo General del Poder Judicial, 2006.

2 Para Manuel Castells, o paradigma da tecnologia da informação está fundado em cinco características: 1. A informação é a sua matéria prima; 2. Penetrabilidade dos efeitos da nova tecnologia (as atividades humanas são afetadas pela tecnologia); 3. Predomínio da lógica das redes (a rede pode ser implementada materialmente em todos os tipos de processos e organizações); 4. Flexibilidade (a rede possui alta capacidade de reconfiguração); 5. Convergência de tecnologias específicas (a tendência natural é de integração de todo o sistema). A sociedade em Rede. 8ạ edição, p. 108. Disponível em: <https://doc-0k-a0-appsviewer.googleusercontent.com/viewer/secure/pdf/3nb9bdfcv3e2h2k1cmql0ee9cvc5lole/2mk9btf1cc8hiboa34 gi46tupbo5dog4/1435328700000/drive/*/ACFrOgAUUgXttSLICF5dovlamwpEAaw_VWVX5wxnm3nrZLSpzjiLg8E b8xmVjJNC-ts0ddDP6pwm64qeGeKmikHsYXb5eTwg_t2jr_dIG3w9louu0ED32dAxMys85TQ=?print=true>. Acesso em 12.12.2015.

${ }^{3}$ Hoje várias são as técnicas de anonimato, como v.g. o IP Spoofing, uso de Proxis anônimos, servidores de correo Web anônimo, utilização de anomimizadores Web, o uso dos cibercentros, que não possuem regulamentação e tampouco fiscalização, o uso de telefonia móvil GPRS com cartão pre-pago para ocultar identidades ou dificultar identificações, uso de redes WIFI alheias e carentes de segurança, uso de programas maliciosos com vírus do tipo troya que permitem o controle remoto de equipes, as técnicas de engenharia social que permitem suplantar identidades capturando senhas e vulnerando o direito à intimidade das vítimas, a exploração de "bugs", o uso de dicionários ou robôs para ataques contra sistemas de criptografia, o envio de vírus e programas que causam danos nos sistemas informáticos e tantos outras técnicas. SALOM CLOTET, Juan. Delito Informático y su investigación, Nuñez, Eloy Velasco, p. 98 (tradução livre). In: VELASCO NUÑEZ, Eloy. Delitos contra y a través de las nuevas tecnologías. ¿Como reducir su impunidad? Cuadernos de Derecho Judicial, III, 2006. Madrid: Consejo General del Poder Judicial
} 
Sob o viés da cultura jurídico-brasileira, Celso Antonio Pacheco Fiorillo analisa que o meio ambiente digital caracteriza-se como uma nova faceta do meio ambiente cultural (art. 216 da Constituição Federal), em razão de uma nova cultura que passa por diversos veículos que revelam um novo processo civilizatório adaptado à sociedade da informação, ou seja, uma nova forma de viver relacionada a uma cultura de convergência em que as emissoras de rádio, televisão, cinema, videogames, internet e demais tecnologias de informação 'moldam uma 'nova vida' que revela, segundo o citado autor, uma nova faceta do meio ambiente cultural ${ }^{4}$. Assim, todos os meios de comunicação existentes na Sociedade da Informação pertencem ao patrimônio cultural brasileiro e devem ser preservados desde que não coloquem em risco a vida e a dignidade da pessoa humana em um sistema ecologicamente equilibrado ${ }^{5}$.

Diante dessa contextualização e da vulnerabilidade presente na sociedade da informação, crimes são praticados no meio ambiente digital como uma nova modalidade criminológica.

\subsubsection{A PROBLEMÁTICA JURÍDICA EM TORNO DA CONCEITUAÇÃO NO MEIO AMBIENTE DIGITAL}

Iniciamos o tema propondo a definição do chamado crime no meio ambiente digital, cibercrime ${ }^{6}$ ou delito informático.

Consideramos que o delito informático, em sentido amplo, caracteriza-se como qualquer comportamento delitivo realizado no ciberespaço (espaço virtual de interação e comunicação pessoal) definido pelo uso das tecnologias de informação e comunicação, dando surgimento a condutas cujo conteúdo ilícito é novo e se relaciona diretamente com os novos interesses ou bens sociais nele existentes, assim como também a comportamentos tradicionalmente ilícitos no quais unicamente mudam em face de serem praticados por internet ${ }^{7}$.

\footnotetext{
${ }^{4}$ Fundamentos constitucionais do meio @mbiente Digit@al na Sociedade da Informação. In: 0 Direito na Sociedade da Informação III. São Paulo :Atlas, 2013, p. 13.

5 : VELASCO NUÑEZ, Eloy. Delitos contra y a través de las nuevas tecnologías. ¿Como reducir su impunidad? Cuadernos de Derecho Judicial, III, 2006. Madrid: Consejo General del Poder Judicial

${ }^{6}$ Há quem prefira a denominação de ciberdelincuencia como expressão mais correta para o neologismo cibercrime. PEREZ Gil. Medidas de investigación y aseguramiento de la prueba en el Convenio sobre el Cibercrimen. Actualidad Penal, n. 36, 2003, p. 896. Para o citado autor, a ciberdelincuencia é un fenómeno delictivo en rápida propagación bajo el cual se englobarían todos aquellos delitos que pueden cometerse por medio de un equipo conectado a una red informática o contra un sistema o equipo informático conectado a la red.

${ }^{7}$ Yvonne Jewkes (Cibercrimen. In: MCLAUGHIN, E. U, MUNCIE, J. The sage dictionary of criminology. London: Sage, 2006)., Eloy Velasco Nuñez (In: Delitos contra y através de las nuevas tecnologías. Como reducir su impunidad?), Carlos Maria Romeo Casabona (In:El cribercrimen nuevos retos jurídico-penales, nuevas respuestas, 2006. Comares, Décimo Congresso das Nações Unidas sobre Prevención del Delito y Tratamiento del Delincuente (Viena, 10 a 17 de abril de 2000) que declara: "Por delito cibernético se entiende todo delito que puede cometerse por medio de un sistema o una red informáticos, en un sistema o una red informáticos o contra un sistema o una red informáticos."
} 
Por internet entenda-se "o sistema constituído do conjunto de protocolos lógicos, estruturado em escala mundial para uso público e irrestrito, com a finalidade de possibilitar a comunicação de dados entre terminais por meio de diferentes redes"

Nesse diapasão, encerramos, apesar das divergências doutrinárias, como crimes cibernéticos (ou cibercrimes) um quadro tipológico dos crimes informáticos, a saber: a) sabotagem informática; b) fraude através de computadores ("pirataria informática”); c) estelionatos eletrônicos; d) spamming (envio em grande escala de publicidade não solicitada); e) lavagem de dinheiro; f) cópia ilegal de software; g) espionagem informática (hacking); h) infração de copyright em bases de dados; i) uso ilegítimo de sistemas informáticos alheios; j) acessos não autorizados; k) interceptação de e-mail; 1) pornografia infantil informática; m) terrorismo (intimidar e causar terror por meio da rede da internet); n) narcotráfico (vender narcotráficos via internet); o) espionagem pessoal (rastrear ações/informações alheias através da internet); p) trafico de armas (compra e venda de armas); q) proselitismo de seitas (com o intuito de gerar fanatismo e finalidade que pode gerar danos à saúde das pessoas, bem estar, privacidade e tranquilidade da pessoa)

\section{OS CRIMES PERPRETADOS EM FACE DO MEIO AMBIENTE DIGITAL E A VIOLAÇÃO AOS DIREITOS HUMANOS: INEGÁVEL SUBSUNÇÃO FÁTICO- JURÍDICA}

\subsection{DIREITOS INSTRUMENTALIZADOS PELA SOCIEDADE DA INFORMAÇÃO E PROTEGIDOS NO MEIO AMBIENTE DIGITAL}

Através da breve digressão acima mencionada sobre as dimensões tipológicas em face do meio ambiente digital geradoras de agressões a direitos fundamentais, torna-se inegável, a constatação da chamada "fragmentação do conhecimento e da comunicação"9

Assim, se de um lado a sociedade da informação instrumentaliza o direito à liberdade de informação: a) liberdade de buscar informação; b) liberdade de difundir a informação; c) liberdade de receber informação, de outro, as ingerências ilícitas podem promover o esvaziamento do direito à informação segura, sem invasões não consentidas e portanto, sem o abuso deste direito ${ }^{10}$.

\footnotetext{
${ }^{8}$ Art. 50, Lei 12965/2014 (Marco Civil da Internet).

9 MATHIAS, Paul. Des libertés numériques. Notre liberte est-elle menaçée par l'internet?. Paris: Presses Universitaires de France, 2008, p. 23 e ss.

10 GARCÍA DE LA CRUZ, Juan Manuel. Delitos informáticos . Universidad Valle del Bravo. Disponível em http://www.ilustrados.com/tema/6521/Delitos-Informaticos.html. Acesso em 12/04/2015.
} 
Podem ainda ser violados os direitos à produção e criação literária, artística, científica e técnica e o direito inerente à proibição de toda e qualquer forma de discriminação, em razão de raça, sexo, cor, religião, opinião ou qualquer outra condição ou circunstância pessoal ou social. Ainda o citado autor ressalta que outras ações que comportem um desapreço à dignidade da pessoa humana, o livre desenvolvimento da personalidade, o respeito à lei e aos direitos dos demais que afetem a ordem política e social podem ser violados através do uso dos instrumentos tecnológicos de comunicação e informação, afrontando dispositivos expressamente estabelecidos na Constituição Espanhola ${ }^{11}$.

$\mathrm{E}$ assim, nesse diapasão incluímos as violações contra o direito à isonomia, o lazer e a ordem democrática de um país.

\subsection{BENS JURÍDICOS TUTELADOS NO MEIO AMBIENTE DIGITAL: NATUREZA JURÍDICA}

Após a digressão acima sobre os bens jurídicos atingidos na criminalidade cibernética, indaga-se: um cibercrime/informático/digital atenta contra direitos considerados humanos?

Preliminarmente é de suma importância citar sobre quais bases principiológicas a sociedade da informação deve estar assentada:

A sociedade da informação assenta sobre o uso óptimo das novas tecnologias da informação e da comunicação, em respeito pelos princípios democráticos, da igualdade e da solidariedade, visando o reforço da economia e da prestação de serviços públicos e, a final da melhoria da qualidade de vida de todos os cidadãos ${ }^{12}$.

Transcrevendo as bases principiólógicas para o ordenamento jurídico constitucional brasileiro, observa-se que:

Assim, entendido constitucionalmente como forma, processo ou veículo destinado a realizar a manifestação do pensamento, a criação, a expressão e a informação, o uso da internet no Brasil em face da presente lei deverá ser interpretado estruturalmente e preliminarmente em face dos princípios, garantias, direitos e deveres fixados pela Constituição Federal Brasileira em proveito dos brasileiros e estrangeiros residentes no País, ou seja, ser interpretado não só a partir dos princípios fundamentais de nossa Constituição indicados nos artigos $1^{\circ}$ a $4^{\circ}$, como também em face do que estabelecem os direitos e as garantias fundamentais (artigos $5^{\circ}$ a 17) bem

${ }^{11}$ ROMEO CASABONA, Carlos Maria. Derecho Penal y libertades de expresión y comunicación en internet. ROMEO CASABONA, Carlos María et al. La adaptación del Derecho Penal al desarrollo social y tecnológico. Granada:Comares, 2010, p.305-306.

${ }^{12}$ MARQUES, Garcia e MARTINS, Lourenço. Direito da Informática. Coimbra: Almedina, 2000, p. 23) 
como as regras superiores que definem as relações normativas no plano da comunicação social (artigos 220 a 224 da CF) ${ }^{13}$

E, discorrendo sobre o tema em face do art. $2^{\circ}$ da Lei 12965/2014, observa-se que o legislador encerrou como fundamentos do uso da internet o que segue ${ }^{14}$ : a) liberdade de expressão; b) reconhecimento da escala mundial da rede; c) os direitos humanos, o desenvolvimento da personalidade e o exercício da cidadania em meios digitais; d) a pluralidade e a diversidade; e) a abertura e a colaboração; f) a livre-iniciativa, a livre concorrência e a defesa do consumidor; g) a finalidade social da rede.

Tecidas as considerações sobre os bens jurídicos tutelados em face da criminalidade digital e observados os fundamentos para o uso da internet, faz-se mister considerar-se a definição de direitos humanos ou direitos do homem.

Inicialmente, a conceituação da expressão direitos humanos ${ }^{15}$, segundo Norberto Bobbio, não é expressão fácil de definição. Afirma tratar-se de expressão vaga e que geralmente, as conceituações são tautológicas:

(...) Direitos do homem são os que cabem ao homem enquanto homem’ Ou nos dizem algo apenas sobre o estatuto desejado ou proposto para esses direitos, e não sobre o seu conteúdo. 'Direitos do homem são aqueles que pertencem, ou deveriam pertencer, a todos os homens, ou dos quais nenhum homem pode ser despojado'. Finalmente, quando se acrescenta alguma referência ao conteúdo, não se pode deixar de introduzir termos avaliativos: 'Direitos do homem são aqueles cujo reconhecimento é condição necessária para o aperfeiçoamento da pessoa humana, ou para o desenvolvimento da civilização $(. . .)^{16}$

Não obstante a crítica encetada pelo doutrinador acima, convém para fins didático-jurídicos a conceituação da expressão de direitos humanos que pode ser assim estabelecida como "valores éticos anteriores ao direito positivo e que segundo George Marlmelstein, estão até mesmo acima do direito positivo. Segundo o citado autor, os direitos humanos possuem um conteúdo muito semelhante ao direito natural, sendo a "matéria-prima" dos direitos

${ }^{13}$ FIORILLO, Celso Antonio Pacheco. Comentários à Lei 12965/2014 : 0 marco civil da internet e o meio ambiente digital na sociedade da informação. São Paulo: Saraiva, 2015 p.16.

${ }^{14}$ Contudo, interessante observar sob a ótica de uma interpretação crítico normativo-constitucional que o artigo em questão não trouxe nenhuma novidade em termos de deveres e direitos já não anteriormente apontados na Carta Magna de 1988. FIORILLO, Celso Antonio Pacheco; FULLER, Greice Patrícia. Tutela Constitucional da Internet no Brasil em face do Meio ambiente digital. In: Os 20 anos da internet no Brasil, seus reflexos no Meio Ambiente Digital e sua tutela jurídica na sociedade da informação. Celso Antonio Pacheco Fiorillo e Regina Célia Martinez (Org). São Paulo:FMU, 2015, v. 1, p. 16.

${ }^{15}$ Ao término da Segunda Guerra Mundial, com a intensificação do processo histórico de reconhecimento dos direitos humanos, foi aprovado como marco paradigmático a Declaração Universal dos Direitos Humanos (1948) e posteriormente, o Pacto Internacional sobre Direitos Civis de Políticos e o Pacto Internacional sobre Direitos Econômicos, Sociais e Culturais, datados ambos de 1966.

A partir daí foram erigidos a direitos fundamentais os direitos à vida, propriedade e liberdade, posteriormente os direitos políticos, sociais, econômicos e culturais e atualmente, o direito ao meio ambiente ecologicamente equilibrado, é dizer, o direito ao meio ambiente digital equilibrado e limitado ao uso lícito de seus recursos.

${ }^{16}$ BOBBIO, Norberto. A Era dos Direitos. Rio de Janeiro: Campus, 1992, p.17. 
fundamentais. Ainda nos remete a outro conceito que assimila a ideia de que os direitos humanos se caracterizam como valores que foram positivados na esfera do direito internacional. Trata-se de visão, compatível com a de índole constitucional, visto que a Carta Magna Brasileira sempre que trata de tratados se refere a "direitos humanos"17.

Pois bem.

Os bens jurídicos tutelados nos crimes digitais chamados mistos podem ser o patrimônio e a honra, como v.g. estelionato, calúnia, injúria, difamação cometidos por meio da rede.

No que se refere aos crimes ditos puros ou próprios, os bens jurídicos protegidos podem ser a propriedade intelectual (no caso, v.g. pirataria de software), intimidade, patrimônio (v.g. conduta delituosa de um cracker que invade o computador destruindo o arquivo do mesmo). Contudo, em todas as modalidades delitivas há um núcleo pétreo de bens jurídicos alvo de tutela jurídico-penal que são a segurança informática, assim como da liberdade.

Em relação à questão atinente à segurança cibernética, observa-se que se trata de um bem jurídico de natureza difusa, podendo atingir um número indeterminado de pessoas geradora de uma situação de conflituosidade social que se contrapõe em relação a interesses de diversos grupos de usuários de internet (usuários pessoas físicas, jurídicas, hackers, crackers, v.g).

Quando se alude no bem segurança jurídica, faz-se necessária a indicação de três elementos fundamentais, quais sejam: a) integridade: a informação deve ser fidedigna e completa, podendo apenas o usuário alterá-la; b) disponibilidade: o usuário deve ter a informação assim que a necessite; c) confidencialidade: não é permito o acesso ou a divulgação de informação sem a anuência do usuário.

Ainda no que tange à segurança da internet vê-se que nos crimes informáticos há um novo bem jurídico a ser tutelado que é a inviolabilidade de dados informáticos, ou, segundo Faria Costa , "o fluxo informacional automizado compreendendo não apenas a privacidade de tais dados, mas também, e talvez até principalmente, a integridade dos mesmos".

Partindo-se para o direito à liberdade, como outro bem jurídico central tutelado em face do meio ambiente digital, Greice Patricia Fuller ${ }^{18}$ afirma que (incluindo-se os direitos à liberdade de informar, expressar e comunicar) no desenho social do século XXI, ganhou novos contornos quando houve a ampliação de suas formas de manifestações através do surgimento da sociedade da informação. Nesse diapasão, continua a autora, o poder de comunicação fortaleceu-se, tornando-se cada vez mais rápido e efetivo, havendo a redução incontestável

\footnotetext{
${ }^{17}$ MARMELSTEIN, George. Curso de Direitos Fundamentais. São Paulo: Atlas, 2014, pp. 23-24.

${ }^{18}$ FULLER, Greice Patrícia. O Direito Criminal Difuso, a dignidade da pessoa humana e a mídia na sociedade da informação. IN: Anais do VII Congresso Brasileiro da Sociedade da Informação. São Paulo: FMU, v. 7, nov. 2014, p. 08-09.
} 
das fronteiras territoriais. Entretanto, faz-se mister alertar que essa liberdade de comunicação gerou uma inequívoca diminuição da qualidade da informação disponível, bem como, operou a redução do sentido comunicacional no que tange a interação intersubjetiva pessoal ${ }^{19}$.

Portanto, é de se concluir que a tutela jurídico-penal como expressão instrumentalizada ao anseio de buscar a proteção ao meio ambiente digital é imperiosa, posto que o uso da internet deve:

(...) respeitar os direitos humanos e o desenvolvimento da personalidade, pois se trata de um instrumento tendente à melhoria do desenvolvimento social e cultural do homem (art. $3^{\circ}$ da Constituição Federal Brasileira), sendo uma via através da qual se articula o sentimento de 'pertenecimento' do homem à comunidade, gerando-se assim o fenômeno da inclusão digital e fortalecendo-se a democracia digital (... $)^{20}$

E, porque se deve tal respeito? Justamente porque os direitos violados nas condutas praticadas no seio da sociedade da informação são tidos como humanos, ou seja, próprios do homem, enquanto tal, independentemente das qualificações específicas de raça, sexo, religião, nacionalidade ou posição social.

Analisadas as considerações acima, fácil é perceber que a prática delitiva sob o contexto da sociedade da informação viola frontalmente os direitos humanos, visto que apresentam como bens jurídicos a serem protegidos, direitos inerentes ao princípio da dignidade da pessoa humana, ademais de sua fundamentação ser calcada sobre as bases conceituais deste princípio.

Segundo Greice Patrícia Fuller, a dignidade da pessoa humana apesar de ser reconhecida como conceito a priori, teve seu conceito reconhecido expressamente pela Constituição Federal de 1988 como o valor- matriz dos fundamentos da República Federativa do Brasil. Assim, seguindo sua ideia, a dignidade não pode deixar de ser caracterizada como um "valor fundamental de toda ordem sistêmica refletida no conjunto ideológico presente na citada Carta Magna, assim entendendo a ordem jurídica, político-administrativa, tributária, econômico-financeira, cultural e social”21

\subsection{O DIREITO AO ACESSO À INTERNET COMO DIREITO HUMANO}

\footnotetext{
19 Ibid., p. 09.

${ }^{20}$ FIORILLO, Celso Antonio Pacheco; FULLER, Greice Patrícia. Tutela constitucional da internet no Brasil em face do meio ambiente digital. In: Os 20 anos de internet, seus reflexos no meio ambiente digital e sua tutela jurídica na sociedade da informação. Celso Antonio Pacheco Fiorillo e Regina Celia Martinez (Org). São Paulo: FMU, 2015, V.1, p. 18.

${ }^{21}$ FULLER, Greice Patrícia. 0 meio ambiente hospitalar em face da Dignidade da Pessoa Humana no Direito Ambiental Brasileiro. Revista Brasileira de Direito Ambiental, abr/jun 2011, p. 62.
} 
Em continuidade e no que tange ao tema liberdade de opinião e expressão, a Organização das Nações Unidas (ONU) publicou relatório sobre a promoção e proteção do direito à liberdade de opinião e expressão. No citado documento assevera que impedir o acesso à informação através da internet não só é um crime, senão e sobretudo uma violação dos direitos humanos, caracterizando assim a violação do art. 19, parágrafo $3^{\circ}$ do Pacto Internacional de Direitos Civis e Políticos de 1966 que prescreve ser direito de todo cidadão a liberdade de expressão e acesso à informação por qualquer tipo de veículo.

Portanto, o direito ao acesso à internet foi contemplado pela ONU como direito humano ${ }^{22}$. Assim explica-se por considerar-se que o bloqueio ao acesso à internet gera violação ao direito à liberdade de expressão e informação, liberdades essas consideradas como básicas.

A ONU ainda chegou a declarar que a internet "se tornou um instrumento indispensável para que grande parte dos direitos humanos seja respeitada. ${ }^{23}$ " Contudo, há quem afirme que a tecnologia "é um importante meio que possibilita alcançar liberdades básicas" ${ }^{24}$ ", o que não quer dizer que seja um direito em si, mas um meio que possibilita o direito à liberdade de expressão e informação.

De toda forma, assim não foi o entendimento da ONU, sendo que o relatório elaborado pelo Conselho de Direitos Humanos da ONU, apresentou como motivação o fato de que em alguns países (como v.g. França em 2010) houve a exclusão ao acesso à internet de pessoas que cometeram infrações referentes a direitos autorais. Nesse sentido, a revista Wired ainda publicou que o acesso à rede na Síria vem sendo bloqueado quando de manifestações da população desde 2011.

Diante de tal cenário, o relatório da ONU estabeleceu peremptoriamente que nenhum Estado pode interromper o acesso à internet em nenhuma ocasião e nem por motivações de ordem política ou econômica, justamente por ser a liberdade ${ }^{25}$ - bem jurídico-penal tutelado - um direito humano.

\footnotetext{
22 Assembléia Geral da Organização Geral das Nações Unidas. Report of the Special Rapporteur on the promotion and protection of the right to freedom of opinion and expression, Frank La Rue*. Disponível em <http://www2.ohchr.org/english/bodies/hrcouncil/docs/17session/A.HRC.17.27_en.pdf> Acesso em 15.01.2016.

${ }^{23}$ Assembléia Geral da Organização Geral das Nações Unidas, op. cit.

${ }^{24}$ VINTON, G. Gerf. Estadão. A internet e os direitos humanos. Disponível em: <http:www.internacional.estadao.com.br>. Acesso em 10.01.2016.

25 Sobre o assunto referente aos limites da liberdade de expressão (inclusive e especialmente no meio ambiente digita), vide acórdão da lavra do Ministro Celso de Mello, ADPF 187, j. 15.06.2011:

"VIII. A liberdade de manifestação do pensamento: um dos mais preciosos privilégios dos cidadãos

Tenho sempre enfatizado, nesta Corte, Senhor Presidente, que nada se revela mais nocivo e mais perigoso do que a pretensão do Estado de reprimir a liberdade de expressão, mesmo que se objetive, com apoio nesse direito fundamental, expor idéias ou formular propostas que a maioria da coletividade repudie, pois, nesse
} 
Justamente por esta razão, o Direito Penal, em legislações de diversos países, como França, Inglaterra, Brasil optou por tutelar o acesso ao uso da internet. Algumas de forma mais tímida e ainda iniciais outras, mais abrangentes, sendo que de toda forma, houve a escolha pela intervenção penal.

Apesar de argumentos contrários e postulados sobre a ideia de que se estaria diante da sociedade de risco $^{26}$ impeditiva de intervenção jurídico-penal, faz-se mister considerar a relevâncias dos bens jurídicos tutelados no arcabouço do meio ambiente digital (direitos humanos) e, para além disso, a observância de que o princípio da razoabilidade assim o permite.

De toda forma, considera-se dentro da sociedade do século XXI e com base no próprio valor da dignidade da pessoa humana ${ }^{27}$ que o direito ao acesso ao uso de internet é possuidor natureza de direitos humanos.

Nesse diapasão importante frisar a lição abaixo transcrita:

O homem como espécie, e cada homem em individualidade, é propriamente insubstituível: não tem equivalente, não pode ser trocado por coisa alguma. Mais ainda: o homem não é só o único ser capaz de orientar suas ações em função de finalidades racionalmente percebidas e livremente desejadas, como é, sobretudo, o único ser cuja existência, em si mesma, constitui um valor absoluto, isto é, um fim em si e nunca um meio para a consecução de outros fins. É nisto que reside, em última análise, a dignidade humana ${ }^{28}$.

Não há, portanto, como negar a natureza de um direito humano ao direito ao meio ambiente digital e seu acesso, posto que os direitos materiais ligados a ele são indispensáveis ao desenvolvimento da condição humana, especialmente no que tange às liberdades e ao tema ligado à inclusão social (digital).

tema, guardo a convicção de que o pensamento há de ser livre, sempre livre, permanentemente livre, essencialmente livre. Torna-se extremamente importante reconhecer, desde logo, que, sob a égide da vigente Constituição da República, intensificou-se, em face de seu inquestionável sentido de fundamentalidade, a liberdade de manifestação do pensamento. Ninguém desconhece que, no contexto de uma sociedade fundada em bases democráticas, mostra-se intolerável a repressão estatal ao pensamento.

(...) Cabe relembrar, neste ponto, a própria Convenção Americana sobre Direitos Humanos (Pacto de São José da Costa Rica), cujo Art. 13, § 5o, exclui, do âmbito de proteção da liberdade de manifestação do pensamento, "toda propaganda a favor da guerra, bem como toda apologia ao ódio nacional, racial ou religioso que constitua incitação à discriminação, à hostilidade, ao crime ou à violência (...)"

${ }^{26}$ Sobre o tema vide CAMARGO, Antonio Luis Chaves. Sistema de penas, dogmática jurídico-penal e política criminal. São Paulo: Cultural Paulista, 2002, p. 195.

${ }^{27}$ Em relação ao Brasil, o princípio da dignidade da pessoa humana é considerado como um dos fundamentos do Estado Brasileiro (art.1ํㅡ, inc. III da CF), cujos objetivos são os de construir uma sociedade livre, justa e solidária; garantir o desenvolvimento nacional, erradicar a pobreza e a marginalização; reduzir as desigualdades sociais e regionais; e promover o bem de todos, sem preconceitos de origem, raça, sexo, cor, idade e quaisquer outras formas de discriminação (art. 3o, incisos I a IV da CF).

${ }^{28}$ COMPARATO, Fabio Konder. Fundamento dos direitos humanos. Cultura dos Direitos Humanos. Maria Luiza Marcílio e Lafaiete Pussoli (Orgs). São Paulo: LTr, p. 72-73. 
Assim é o entendimento de Celso Lafer, afirmando que o direito ao meio ambiente ecologicamente equilibrado é um típico direito de terceira geração que assiste, de modo subjetivamente indeterminado, a todo o gênero humano, justificando assim, especial obrigação que incumbe à coletividade e ao Estado a preservação e a defesa para as presentes e futuras gerações ${ }^{29}$.

Ora, se o meio ambiente ecologicamente equilibrado bem como o meio ambiente digital (que deriva do próprio meio ambiente cultural e consequentemente, do meio ambiente holisticamente considerado)são considerados direitos fundamentais, não há como negar, portanto, o caráter de fundamentalidade e essencialidade ao próprio acesso ao uso da internet.

\section{SOCIEDADE DA INFORMAÇÃO E PAÍSES CENTRAIS E PERIFÉRICOS: REALIDADES CONTRAPOSTAS E RAÍZES DO DESUMANO}

Certo é que o mundo virtual ou a chamada cibercultura ${ }^{30}$ se faz presente em quase todas as esferas sociais dos países centrais ou dos grandes periféricos (emergentes) ou periféricos.

Entre a dialética dos países centrais e periféricos, encontram-se os chamados emergentes, nos quais estariam, especialmente os BRICS (Brasil, Rússia, Índia e China). Tais denominações levam em consideração vários fatores estabelecidos:

Centro y periferia son conceptos complementários y antagónicos que sirven para comprender las relaciones entre espacios desigualmente desarrollados. La noción de centro se aplica tanto al interior de la ciudad como a escala de los Estados y del mundo. En centro se asocia a la idea de poder y dominio, comporta una población importante, una capacidad notable de producción y un nivel de vida alto. Su potencial de innovación atrae a la población y favorece la polarización espacial de desarrollo. Por el contrario, la periferia tiene un nivel de vida menos elevado y sufre relaciones de dependencia de todo tipo. En la periferia, las producciones son menos elaboradas (...) A escala mundial, los países no desarrollados son casos típicos de periferias ${ }^{31}$.

Importante frisar que não obstante haja no cenário fático a violação dos limites ao uso da internet (através do cometimento de práticas delitivas na e através da internet), as tecnologias de informação e comunicação também propiciam disseminação de cultura, promoção da igualdade através da inclusão social, a reestruturação do Estado a partir do e-gov (governo eletrônico) e das próprias relações sociais (através de e-mail, chats on-line e redes sociais).

\footnotetext{
${ }^{29}$ LAFER, Celso. A reconstrução dos direitos humanos. São Paulo: Companhia das Letras, 1988, p. 131-132.

30 O neologismo"cibercultura" estabelece o conjunto de técnicas (materiais e intelectuais), de práticas, de atitudes, de modos de pensamentoede valores que se desenvolvem juntamente com o crescimento do ciberespaço. LEVY, Pierre. Cibercultura. Trad. Carlos Irineu da Costa. São Paulo: Ed. 34, 1999, p. 17.

${ }^{31}$ ZARATE MARTIN, Manuel Antonio; RUBIO BENITO, Maria Tereza. Geografia Humana: sociedade, economia y território. Madrid: Editoria Universitaria Ramon Areces, p. 11.
} 
Todos os computadores conectados à rede denominada Internet ${ }^{32}$ ficam interligados entre si permitindo o acesso à informação de forma quase que instantânea, de qualquer lugar do mundo. Esta conexão pode ser feita por: cabos, satélites e redes telefônicas. Em face desta facilidade, a Internet rapidamente se popularizou.

Nesse ponto, imperiosa faz-se a seguinte indagação, a saber: o fato de ser um país considerado periférico ou central gera consequências quanto ao direito de acesso ao uso da internet? A resposta que se impõe é afirmativa. Senão vejamos.

Assim, como termos avaliativos do mencionado acima, verifica-se que em novembro de 2014 a rede mundial de computadores já tinha aproximadamente 3 bilhões de usuários, ou seja, $40 \%$ de toda a população mundial ${ }^{33}$. No que pertine mais especificamente ao Brasil, de acordo com os dados divulgados pela Pesquisa Nacional por Amostra de Domicílios (PNAD) de 2013, do Instituto Brasileiro de Geografia e Estatística - IBGE ${ }^{34}$. Segundo os dados, no Brasil, aproximadamente 95,4 milhões de pessoas de 10 anos ou mais de idade acessaram a internet por meio de microcomputador no período de referência da PNAD (28/09/2013 a 27/09/2014), um crescimento de 11,4\% (ou 9,8 milhões de usuários) em relação ao ano de $2013^{35}$. Pela primeira vez, a proporção de internautas passou da metade da população residente, saindo de 49,4\% em 2013 para 54,4\% em 2014. Em todas as grandes regiões, houve crescimento do contingente de internautas: $19,3 \%$ no Norte, $14,6 \%$ no Nordeste, $9,5 \%$ no

\footnotetext{
${ }^{32}$ A Internet é um sistema global de rede de computadores que possibilita a comunicação e a transferência de arquivos de uma máquina a qualquer outra máquina conectada na rede, possibilitando, assim, um intercâmbio de informações sem precedentes na história, de maneira rápida, eficiente e sem a limitação de fronteiras, culminando na criação de novos mecanismos de relacionamento. CORREA, Gustavo Testa. Aspectos Jurídicos
} da Internet. 5a ed. Saraiva, 2010, p. 25 . Disponível em: <http://integrada.minhabiblioteca.com.br/books/9788502112537/page/26> Acesso em 10.12.2015.

33 Internet já tem quase 3 bilhões de usuários no mundo, diz ONU. Disponível em: <http://www1.folha.uol.com.br/tec/2014/11/1553088-internet-ja-tem-quase-3-bilhoes-de-usuarios-nomundo-diz-onu.shtml>. Acesso em 12.04.2015.

${ }^{34}$ IBGE. Tecnologia: número de pessoas que acessam a internet por computador cresce $11,4 \%$ em um ano. Disponível em < http://saladeimprensa.ibge.gov.br/noticias.html?view=noticia\&idnoticia=3030>. Acesso em 14.01.2016.

${ }^{35} \mathrm{O}$ acesso à internet em domicílios chegou a 85,6 milhões de brasileiros, o equivalente a 49,4\% da população, segundo indica pesquisa divulgada pelo IBGE nesta quarta (29). Os dados são referentes a Pesquisa Nacional por Amostra de Domicílios (PNAD) de 2013. A pesquisa considerou o acesso de pessoas acima de 10 anos de idade que utilizaram a internet pelo menos uma vez em um período de 90 dias anteriores à realização das entrevistas. PORTAL EBC. Acesso à internet chega a $49,4 \%$ da população brasileira. Disponível em <http://www.ebc.com.br/tecnologia/2015/04/acesso-internet-chega-494-da-populacao-brasileira>. Acesso em 10.01.2016. Ver ainda: IBGE. Segundo dados do IBGE: "A pesquisa suplementar sobre acesso à Internet e posse de telefone móvel celular para uso pessoal ampliou a investigação rotineira da PNAD, que restringe o levantamento sobre o assunto à captação da existência, na unidade domiciliar, de telefone móvel celular e de microcomputador ligado à Internet. Alguns resultados preliminares desse levantamento, que abrangeu a população de 10 anos ou mais de idade, foram antecipados por ocasião da divulgação das informações da pesquisa básica e agora estão inseridos no contexto completo do levantamento suplementar". Disponível em http://www.ibge.gov.br/home/estatistica/populacao/acessoainternet/comentarios.pdf.

Acesso em 10.01.2016. 
Sudeste, $10,0 \%$ no Sul e 12,0\% no Centro-Oeste. No que tange à posse de telefone celular para uso pessoal houve um incremento de 4,9\% em 2014 (6,4 milhões de pessoas a mais), totalizando 136,6 milhões de pessoas de 10 anos ou mais de idade que tinham o aparelho.

Entretanto, na África vê-se um abismo grande no que tange ao uso da internet em comparação ao Brasil e União Europeia ${ }^{36}$. Assim, segundo dados de Worldstats, observa-se que os usuários de internet na África perfazem um total de 9,8\% em face de todo o restante do mundo que inclui a cifra de 90,2\%. Em termos de porcentagem de penetração da internet em cada cidade temos: Nigéria, 92,7\%; Egito, 48, 3\%; Kenya 31,9\%; Africa do Sul 26,8\%; Marrocos 20,2\%; Sudão, 9,3\%; Uganda 8,5\%; Tanzania 7,6\%; Argelia 7,2\% e Tunísia 5,4\% 37.

Em relação à América do Norte, a integração na internet é de 87,9\%; América do Sul 61\%, América Central, 46,8\% e Caribe $41,9 \%^{38}$. E no que tange à União Europeia a porcentagem é de $83,1 \%{ }^{39}$.

Diante do cenário acima desenhado em linhas de realidade do mundo fenomênico, pode-se concluir pelo profundo abismo existente no que tange ao acesso ao uso da internet, o que por certo, seria de alvitre privilegiar-se o princípio da solidariedade franqueado desde a Declaração dos Direitos do Homem de 1948.

O quadro referente ao índice de porcentagem de penetração da internet no mundo mostra a exclusão econômica ${ }^{40}$, intelectual e digital existente entre os países periféricos e centrais e que os níveis de instrução (escolaridade) e renda afetam significativamente o número de usuários $^{41}$.

\footnotetext{
${ }^{36}$ Internet Usage Statistics for Africa. Disponível em http://www.internetworldstats.com/stats1.htm. Acesso em 14/01/2016.

${ }^{37}$ Internet Usage Statistics for Africa, op.cit.

38 Internet Usage Statistics for all the Americas. Disponível em $<$ http://www.internetworldstats.com/stats2.htm>. Acesso em 14/2/2016.

${ }^{39}$ Internet Usage Statistics for European Union. Disponível em $<$ http://www.internetworldstats.com/stats9.htm>. Acesso em 14/02/2016.

${ }^{40}$ Assim corresponde a seguinte ideia: "El problema que se plantea es entonces el siguiente: si a la economía le cuesta absorber a los exluidos de la riqueza, ¿̇por qué no hay una solidariedad fortalecida que logre conjurar los efectos de exclusión a los que la sociedad expone a los segmentos más vulnerables de su población? En otros términos ¿por qué pareciera que la polítca sufre la misma dificultad que la economía cuando se trata de integrar a sus 'excluídos'? COHEN, Daniel. Riqueza del mundo, pobreza de las naciones. Trad. Sonia Garzonio. Buenos Aireis: Fondo de Cultura Económico, 1997, p. 109.

${ }^{41}$ Como exemplo é possível citar-se o caso do Brasil. Através de pesquisa realizada pelo IBGE, observou-se que: "Quanto mais elevado era o nível de instrução, maior foi a proporção de usuários da Internet(...) A parcela dos usuários da Internet foi mais expressiva no contingente que era estudante e ocupado do que naqueles em que as pessoas se enquadravam somente em uma destas duas condições ou em nenhuma delas. No grupo das pessoas ocupadas que também eram estudantes, a parcela que acessou a Internet atingiu $39,1 \%$ e, no dos indivíduos que não eram estudantes nem ocupados, fi cou em 7,8\% (...) No grupo de usuários da Internet na faixa de sem rendimento a 1 salário mínimo de rendimento mensal domiciliar per capita, 16,7\% acessaram esta
} 
Por fim e sob outro viés, cabe-nos pensar sobre o quadro paradoxal de políticas nacionais que se pretendem nos países, incluindo o Brasil. Na Índia ${ }^{42}$, em 2008, segundo relato de Marcelo Neri, existe um programa chamado "Hole in the wall" ${ }^{43}$, no qual crianças muito pobres têm acesso a computador a céu aberto, levando-se a inclusão digital às mesmas. Contudo, ao lado das paredes onde os computadores se encontram, há outros buracos no chão, onde o esgoto se encontra fluindo a céu aberto ${ }^{44}$. Ademais, como uma criança doente pode usufruir do acesso à internet se antes necessita exercitar direitos vitais vinculados também à dignidade da pessoa humana como, v.g. saúde, educação e moradia sustentável?

No Brasil também há o mesmo programa intitulado " um computador por criança”, inspirado na iniciativa americana OLPC (One Laptop per child). Segundo Marcelo Neri ${ }^{45}$, o certo seria a seguinte iniciativa: "Uma privada decente por família"(UPDF). ${ }^{46}$

Segundo dados da UNICEF, 1 bilhão e 100 milhões de pessoas ainda não têm acesso ao banheiro, sendo que $81 \%$ desse total vive em 10 países (Índia, Indonésia, China, Etiópia, Paquistão, Nigéria, Sudão, Nepal, Brasil e Niger), sendo o Brasil considerado o $9^{\circ}$ nesse ranking de países com o pior nível de saneamento básico, permanecendo atrás da Nigéria, Sudão e Nepal ${ }^{47}$.

rede no domicílio em que moravam e, para aqueles do grupo de mais de 5 salários mínimos, este percentual atingiu $81,1 \%$. Para as pessoas que utilizaram a Internet no local de trabalho, esses indicadores foram, respectivamente, 20,9\% e 57,7\%." IBGE. Disponível em http://www.ibge.gov.br/home/estatistica/populacao/acessoainternet/comentarios.pdf. Acesso em 10.01.2016.

${ }^{42}$ Em Dharavi, uma zona populosa de Mumbai, na Índia, há um único banheiro para cada 1.440 pessoas, e na estação das chuvas as enxurradas transformam as ruas da cidade em rios de excrementos. A fartura de água é, nesse caso, como no de muitas outras cidades do terceiro mundo, uma tragédia: as condições de existência fazem com que a água, em vez de vida, seja muitas vezes instrumento de doença e morte. In: WATKINS, Kevin et al. A água para além da escassez: poder, pobreza e a crise mundial da água. UND.Org. Disponível em: $<$ http://www.hdr.und.org/hdr>. Acesso em: 08. 02. 2009.

${ }^{43}$ Hole-in-the-wall: Lighting the spark of learning. Disponível em <http:www.hole-in-the-wall.com>. Acesso em 15.01.2016. In: FULLER, Greice Patrícia, Tese de Doutorado apresentada na Pontifícia Universidade Católica de São Paulo, intitulada $\mathrm{O}$ Saneamento ambiental como condição primacial à sadia qualidade de vida e fator estruturante do Estado Democrático de Direito Brasileiro, 2011, p. 108.

${ }^{44}$ FULLER, Greice Patrícia Fuller. O Saneamento ambiental..., p. 108.

${ }^{45} \mathrm{O}$ economista acima, do Centro de Políticas Sociais do Instituto Brasileiro de Economia e da Fundação Getúlio Vargas, aponta de forma lapidar a situação paradoxal evidenciada nos países com índices mais baixos de saneamento, como a Índia e o Brasil. Como um país pode pensar primeiro em melhoria tecnológica se ainda doenças, como esquistossomose, que antes era comum apenas em zonas rurais, hoje atinge mais de $80 \%$ das áreas urbanas, perfazendo um total de 04 milhões de pessoas atingidas? Isto para não falar em outras doenças que já tinham sido erradicadas do contexto sanitário nacional como febre amarela e lepra.

${ }^{46} \mathrm{NERI}$, Marcelo. Saneamento é saúde na infância. In: NERI, Marcelo; FERREIRA, Cristina Targa

(Org.). 0 paradoxo da hepatite A. São Paulo: Sanofi Pasteur, [s.d.]. p. 2.

${ }^{47}$ Unicef and World Health Organization. PROGRESS on sanitation and drinking water.

2010. Disponivel em <http://apps.who.int/iris/bitstream/10665/81245/1/9789241505390_eng.pdf> Acesso em 01.02.2011. 
Infelizmente, o número de crianças mortas por diarreia já ultrapassou o número de pessoas mortas em todos os conflitos armados desde a Segunda Guerra Mundial ${ }^{48}$, sendo que a cada oito segundos uma criança morre por beber agua sem tratamento ${ }^{49}$ :

A quantidade de água suja significa que mais pessoas morrem atualmente por causa da água poluída e contaminada do que por todas as formas de violência, incluindo as guerras (Programa do Meio Ambiente das Nações Unidas).

Portanto, pode-se afirmar, segundo Greice Patrícia Fuller ${ }^{50}$, a pobreza pode e deve ser considerada como indicador da insustentabilidade em suas várias vertentes. Em conclusão, para a autora acima, é necessário voltar-se o olhar para a condição humana de vida de milhares e milhares de pessoas, que, à sombra de uma pseudoinvisibilidade, se mantêm como prisioneiras de uma existência sem qualquer qualidade de vida.

Ainda segundo a autora quanto maior a pobreza, maior a condenação a uma vida de mera sobrevivência, reforçando o estigma da violação ao princípio da isonomia e da liberdade ${ }^{51}$.

\section{CONCLUSÕES}

O trabalho analisando a questão inerente à sociedade da informação e aos crimes praticados no meio ambiente digital (crimes digitais, informáticos ou cibercrimes) sob o viés dos direitos humanos no contexto dos países centrais e periféricos, estabelece a conclusões sobre vários pontos, a saber:

a) a debate sobre a conceituação do arquétipo tipológico das condutas violadoras do meio ambiente digital, contudo, houve a assunção da acepção ampla para considerar qualquer conduta realizada no ciberespaço;

b) os direitos humanos são aqueles próprios do homem, independentemente de qualificações, tendo como supedâneo ético-jurídico o princípio da dignidade da pessoa humana;

c) os direitos violados nas condutas contra o meio ambiente digital como os direitos à segurança jurídica e a liberdade (informação, comunicação, expressão), intimidade e honra são dotados de natureza de direitos humanos;

d) o direito ao acesso à internet deve ser analisado como direito humano, visto violar o direito à liberdade e isonomia, e assim, o princípio da dignidade da pessoa humana;

e) verifica-se através de dados científicos e empíricos a realidade paradoxal existente entre o exercício de direitos humanos, sob o viés dos países centrais e periféricos, observando-se

\footnotetext{
${ }^{48}$ Sobre o assunto ver: REUTERS ÁGUA poluída mata mais que violência no mundo. Disponível em: <Http://www.ultimosegundo.ig.com.br>. Acesso em: 23 mar. 2010.

49 Ibid., p. 17.

${ }^{50}$ FULLER, Greice Patrícia. O Saneamento ambiental..., p. 97'e 108.

${ }^{51}$ FULLER, Greice Patrícia. O Sanemento ambiental...,, p. 108.
} 
assim que o acesso ao uso da internet depende de fatores inerentes à renda, escolaridade e trabalho e que sua ausência ou bloqueio geram inequivocamente a exclusão digital, o reforço à desigualdade e o desestímulo à informação e comunicação;

f) a pobreza nos países periféricos enquanto fator de insustentabilidade será verdadeiro obstáculo à consecução de direitos humanos como vida, liberdade, educação e acesso ao uso da internet.

\section{REFERÊNCIAS}

ASSEMBLÉIA GERAL DA ORGANIZAÇÃO GERAL DAS NAÇÕES UNIDAS. Report of the Special Rapporteur on the promotion and protection of the right to freedom of opinion and expression, Frank La Rue*. Disponível em <http://www2.ohchr.org/english/bodies/hrcouncil/docs/17session/A.HRC.17.27_en.pdf> Acesso em 15.01.2016.

BOBBIO, Norberto. A Era dos Direitos. Rio de Janeiro: Campus, 1992.

CAMARGO, Antonio Luis Chaves. Sistema de penas, dogmática jurídico-penal e política criminal. São Paulo: Cultural Paulista, 2002.

CASTELLS, Manuel. A sociedade em Rede. $8^{\text {a }}$ edição, p. 108. Disponível em . Disponível em: $<$ https://doc-0k-a0-appsviewer.googleusercontent.com/viewer/secure/pdf/3nb9bdfcv3e $2 \mathrm{~h} 2 \mathrm{k} 1 \mathrm{cmq} 10 \mathrm{ee} 9 \mathrm{cvc} 5 \mathrm{lole} / 2 \mathrm{mk} 9$ btf1cc8hiboa34gi46tupbo5dog4/1435328700000/drive/*/ACFrOgAUUgXttSLICF5dovlamw pEAaw_VWVX5wxnm3nrZLSpzjiLg8Eb8xmVjJNCts0ddDP6pwm64qeGeKmikHsYXb5eTwg_t2jr_dIG3w9Iouu0ED32dAxMys85TQ=?print=tr ue>. Acesso em 12.12.2015.

COHEN, Daniel. Riqueza del mundo, pobreza de las naciones. Trad. Sonia Garzonio. Buenos Aireis: Fondo de Cultura Económico, 1997.

CLOTET, Juan Salom. Delito informático y su investigación. In: Vazques Nuñez, Eloy. Delitos contra y através de las nuevas tecnologías. ¿Cómo reducir su impunidad? Cuadernos de Derecho Judicial, III. Madrid: Consejo General del Poder Judicial, 2006. 
COMPARATO, Fabio Konder. Fundamento dos direitos humanos. Cultura dos Direitos Humanos. Maria Luiza Marcílio e Lafaiete Pussoli (Orgs). São Paulo: LTr.

CORREA, Gustavo Testa. Aspectos Jurídicos da Internet. 5a ed. Saraiva, 2010, p. 25. Disponível em:

$<$ http://integrada.minhabiblioteca.com.br/books/9788502112537/page/26> Acesso em 10.12.2015.

FIORILLO, Celso Antonio Pacheco. Fundamentos constitucionais do meio ambiente digital na sociedade da informação. In: O Direito na Sociedade da Informação III: a evolução do Direito Digital. São Paulo: Atlas, 2013.

. Curso de Direito Ambiental Brasileiro. São Paulo: Saraiva, 2014

Comentários à Lei 12965/2014:0 marco civil da internet e o meio ambiente digital na sociedade da informação. São Paulo: Saraiva, 2015.

FIORILlO, Celso Antonio Pacheco; FULLER, Greice Patrícia. Tutela Constitucional da Internet no Brasil em face do Meio ambiente digital. In: Os 20 anos da internet no Brasil, seus reflexos no Meio Ambiente Digital e sua tutela jurídica na sociedade da informação.

Celso Antonio Pacheco Fiorillo e Regina Célia Martinez (Org). São Paulo:FMU, 2015, v. 1. FULLER, Greice Patrícia. O meio ambiente hospitalar em face da Dignidade da Pessoa Humana no Direito Ambiental Brasileiro. Revista Brasileira de Direito Ambiental, abr/jun 2011.

O Direito criminal difuso, a dignidade da pessoa humana e a mídia na sociedade da informação. Anais do VII Congresso Brasileiro de Direito da Sociedade da Informação: regulação da mídia na sociedade da informação. São Paulo 16 e 17 de novembro de 2014, v . 7, ISSN 1982-6788.

Tese de Doutorado apresentada na Pontifícia Universidade Católica de São Paulo, intitulada $\mathrm{O}$ Saneamento ambiental como condição primacial à sadia qualidade de vida $\mathrm{e}$ fator estruturante do Estado Democrático de Direito Brasileiro, 2011.

GARCÍA DE LA CRUZ, Juan Manuel. Delitos informáticos . Universidad Valle del Bravo. Disponível em http://www.ilustrados.com/tema/6521/Delitos-Informaticos.html. Acesso em 02.11.2015. 
IBGE. . Tecnologia: número de pessoas que acessam a internet por computador

$\begin{array}{lllllll}\text { cresce } & \mathbf{1 1 , 4 \%} & \text { em } & \text { um } & \text { ano. } & \text { Disponível } & \text { em }\end{array}$ http://saladeimprensa.ibge.gov.br/noticias.html?view=noticia\&idnoticia=3030>. Acesso em 14.01.2016.

.Disponível

em

http://www.ibge.gov.br/home/estatistica/populacao/acessoainternet/comentarios.pdf. Acesso em 10.01.2016.

INTERNET USAGE STATISTICS FOR AFRICA. Disponível em http://www.internetworldstats.com/stats1.htm. Acesso em 14/01/2016.

INTERNET USAGE STATISTICS FOR ALL THE AMERICAS. Disponível em <http://www.internetworldstats.com/stats2.htm>. Acesso em 14/2/2016.

INTERNET USAGE STATISTICS FOR EUROPEAN Union. Disponível em <http://www.internetworldstats.com/stats9.htm>. Acesso em 14/02/2016.

LAFER, Celso. A reconstrução dos direitos humanos. São Paulo: Companhia das Letras, 1988.

LEVY, Pierre. Cibercultura. Trad. Carlos Irineu da Costa. São Paulo: Ed. 34, 1999. MARQUES, Garcia; MARTINS, Lourenço. Direito da informática. Coimbra: Almedina, 2000.

MARMELSTEIN, George. Curso de Direitos Fundamentais. São Paulo:Atlas, 2014.

MATHIAS, Paul. Des libertés numériques. Notre liberte est-elle menaçée par l'internet?. Paris: Presses Universitaires de France, 2008

NERI, Marcelo et al. Saneamento é saúde na infância. In: NERI, Marcelo; FERREIRA, Cristina Targa(Org.). O paradoxo da hepatite A. São Paulo: Sanofi Pasteur, [s.d.].

ONU. Internet já tem quase 3 bilhões de usuários no mundo, diz ONU. Disponível em: <http://www1.folha.uol.com.br/tec/2014/11/1553088-internet-ja-tem-quase-3-bilhoes-deusuarios-no-mundo-diz-onu.shtml>. Acesso em 12.04.2015. 
PEREZ Gil. Medidas de investigación y aseguramiento de la prueba en el Convenio sobre el Cibercrimen. Actualidad Penal, n. 36, 2003.

PORTAL EBC. Acesso à internet chega a 49,4\% da população brasileira. Disponível em <http://www.ebc.com.br/tecnologia/2015/04/acesso-internet-chega-494-da-populacaobrasileira>. Acesso em 10.01.2016.

REUTERS. Água poluída mata mais que violência no mundo. Disponível em: <Http://www.ultimosegundo.ig.com.br>. Acesso em: 23 mar. 2010

ROMEO CASABONA, Carlos María. De los delitos informáticos al cibercrimen: na aproximación conceptual y político-criminal. In: El cibercrimen. Nuevos retos jurídicopenales, nuevas respuestas político-criminales. ROMEO CASABONA, Carlos María (Coord.) Granada: Comares, 2006.

.Derecho Penal y libertades de expresión y comunicación en internet.

UNICEF AND WORLD HEALTH ORGANIZATION. Progress on sanitation and drinking water.

$2010 . \quad$ Disponível em <http://apps.who.int/iris/bitstream/10665/81245/1/9789241505390_eng.pdf> Acesso em 01.02.2011.

VELASCO NUÑEZ, Eloy. Delitos contra y a través de las nuevas tecnologías. Como reducir su impunidad? Cuadernos de Derecho Judicial, III, 2006. Madrid: Consejo General del Poder Judicial.

VINTON, G. Gerf. Estadão. A internet e os direitos humanos. Disponível em: <http:www.internacional.estadao.com.br>. Acesso em 10.01.2016.

WATKINS, Kevin et al. A água para além da escassez: poder, pobreza e a crise mundial da água. UND.Org. Disponível em: 〈http://www.hdr.und.org/hdr>. Acesso em: 08. 02. 2009.

ZARATE MARTIN, Manuel Antonio; RUBIO BENITO, Maria Tereza. Geografia Humana: sociedade, economia y território. Madrid: Editoria Universitaria Ramon Areces. 